\title{
SHORT TERM VARIABILITY OF REEF PROTECTED BEACH PROFILES: AN ANALYSIS USING EOF
}

\author{
J.J. Muñoz-Pérez ${ }^{1}$ and R. Medina ${ }^{2}$ \\ ${ }^{1}$ Applied Physics Dept. Sea Sciences Faculty. Univ. of Cadiz. CASEM. Puerto Real, Cadiz, \\ Spain.juanjose.munoz@uca.es. \\ ${ }^{2}$ Ocean \& Coastal Resarch Group. E.T.S.I. de Caminos. University of Cantabria. Avda. de los \\ Castros s/n. 39005 Santander. Spain. Fax: +34 942 201860, medinar@unican.es.
}

\begin{abstract}
Victoria beach (SW Spain) has a rocky flat at the northernmost zone. This has allowed to choose one profile and monitoring the changes induced by a single day storm. Topographic data taken during 21 days and different tendencies of the beach profile, as the accretion rate, were identified. The analysis is carried out by means of Empirical Orthogonal Function (EOF) techniques, in order to separate the spatial from the temporal variability of the beach profile data.

Among the conclusions, it should be highlighted that a swing or oscillation point of the profile was found around the intertidal zone. Furthermore, the erosion has been irreversible in a short term, and the recuperation consisted only in a modification of the slopes of the emerged part, trying to assimilate them to the ones before the storm.
\end{abstract}

\section{INTRODUCTION}

Areas of hard bottom are encountered in many beaches (e.g. coral reefs, perched beaches) in which, therefore, the entire profile is not sand rich. Many characteristics and informative details about this kind of beaches, which will be denoted as reefprotected beaches, have been previously studied: water level fluctuations (Karunarathana and Tanimoto, 1995), bore-like surf beat (Nakaza and Hino, 1990), sediment flux (Roberts, 1980), wave set-up and cross reef currents (Symonds et al., 1995), wave breaking and wave attenuation over submerged horizontal shelves (Horikawa and Kuo, 1966; Gerritsen,1980; Seelig, 1983; Gourlay, 1994; Nelson, 1994; Yu et al., 1995; Hardy and Young, 1996).

Moreover, the influence of the reef on the A parameter of the useful Dean's (1977) formula, according to the criticism stated by Pilkey et al. (1993), has also been considered (Muñoz-Perez et al., 1999). Both methods (Dean's and Empirical Orthogonal Functions) complement each other and make it possible to obtain a multifarious representation of the phenomenon and the mechanisms that affect these profiles.

Nevertheless, the changes induced in a profile by a single storm have not been described yet. The aim of this article is to explain the evolution and behaviour 
tendencies of a reef-protected profile in the very short term (changes experimented after one storm).

\section{STUDY AREA}

Victoria is a $3 \mathrm{~km}$ long beach located in the Gulf of Cadiz, facing the Atlantic Ocean on the SW coast of Spain, near the Strait of Gibraltar (fig.1).

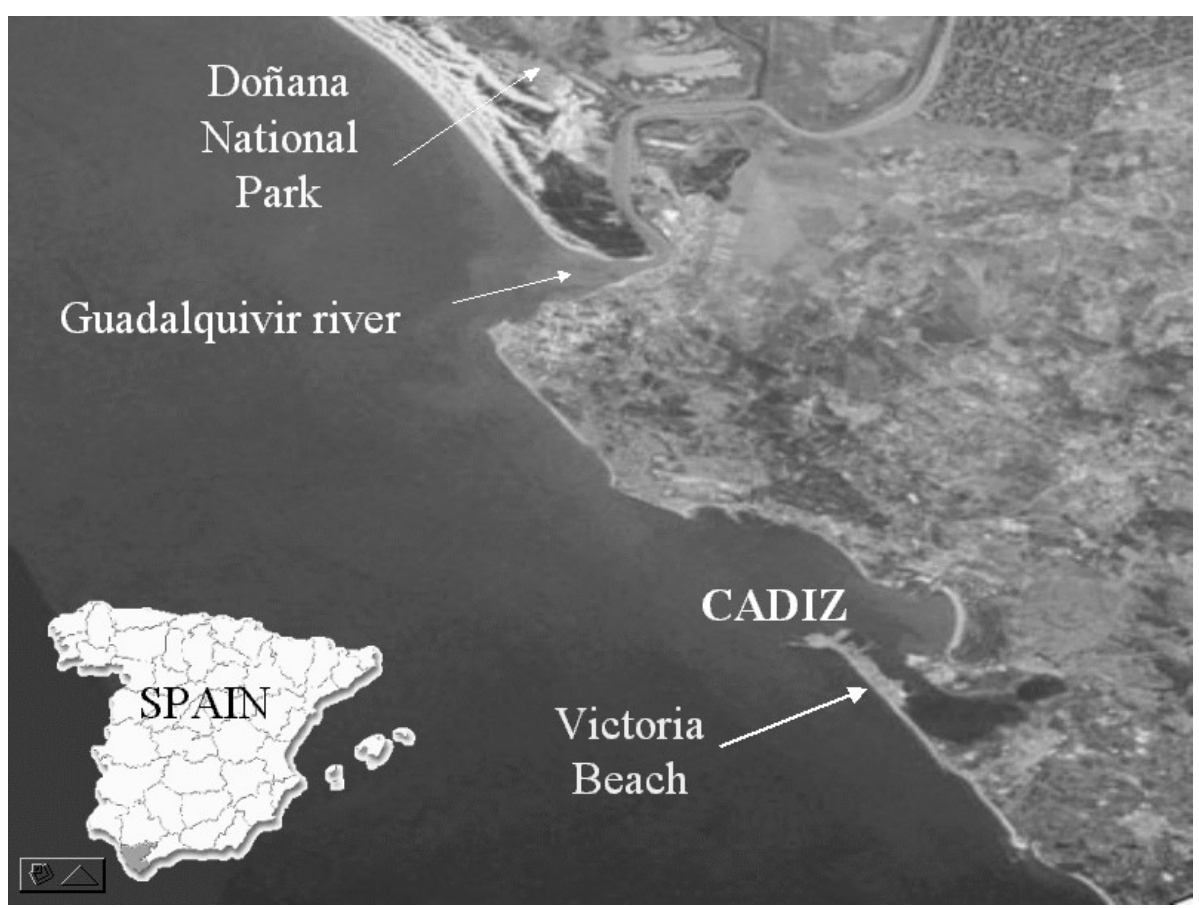

Fig. 1 Location map with an aerial view of the littoral of Cadiz

Its former dune was occupied by the last development of the city of Cadiz (figures 2 and 3 show the difference between the 50's and 90's coastline) and a promenade whose seawall serves as heading of our control profiles.

The region has a mesotidal range with a medium neap to spring variation (1.20-3.50 meters). The sand is $90-95 \%$ quartz and $5-10 \%$ bioclastic material and $0.25 \mathrm{~mm}$ as an average size. There is a plio-quaternary outcrop, a bioclastic conglomerate mostly composed by oysters and pecten shells, which lays in disconformity with the Pliocene rocks and is affected by gravity faults of small throw (Gutierrez-Mas et al., 2003). 


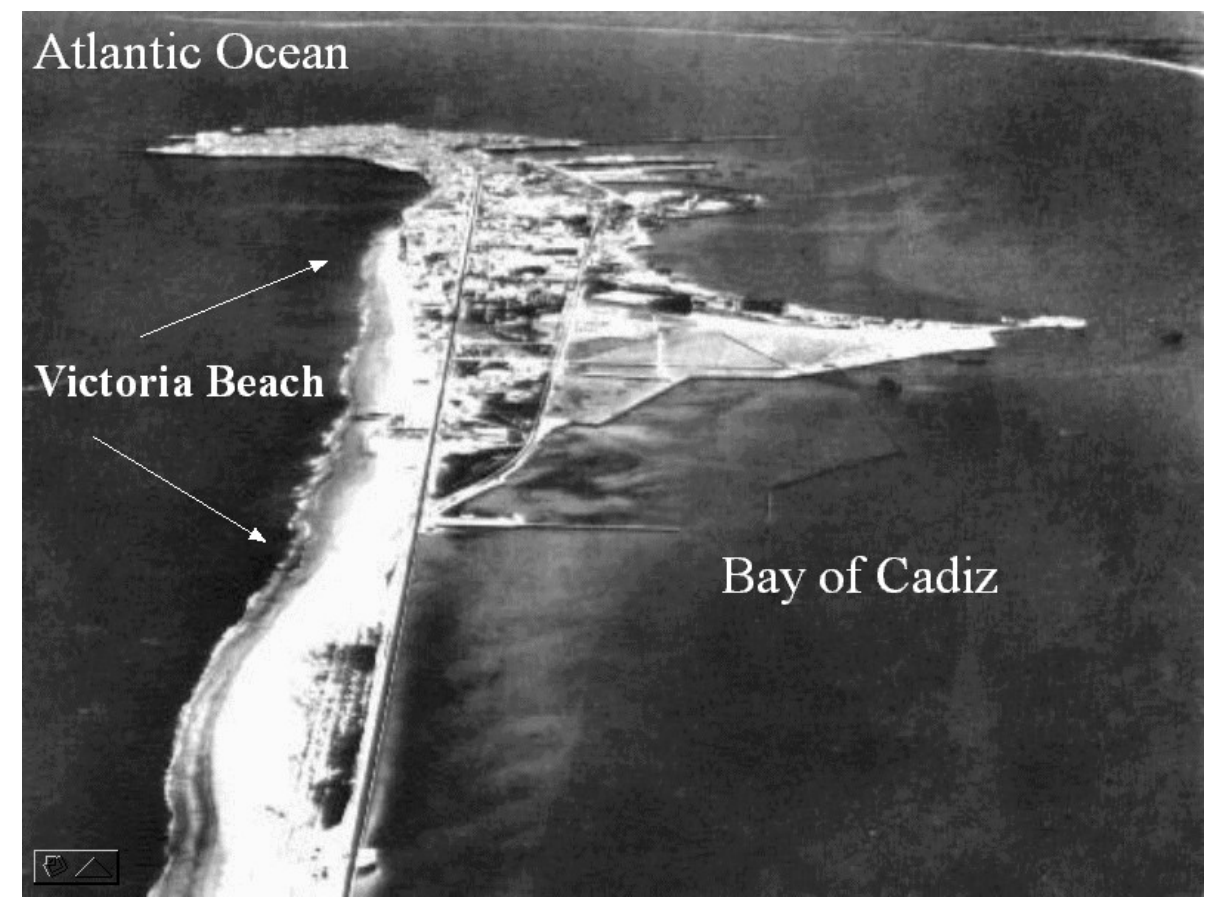

Fig. 2 Littoral coastline at the 50's. No buildings had been edified yet

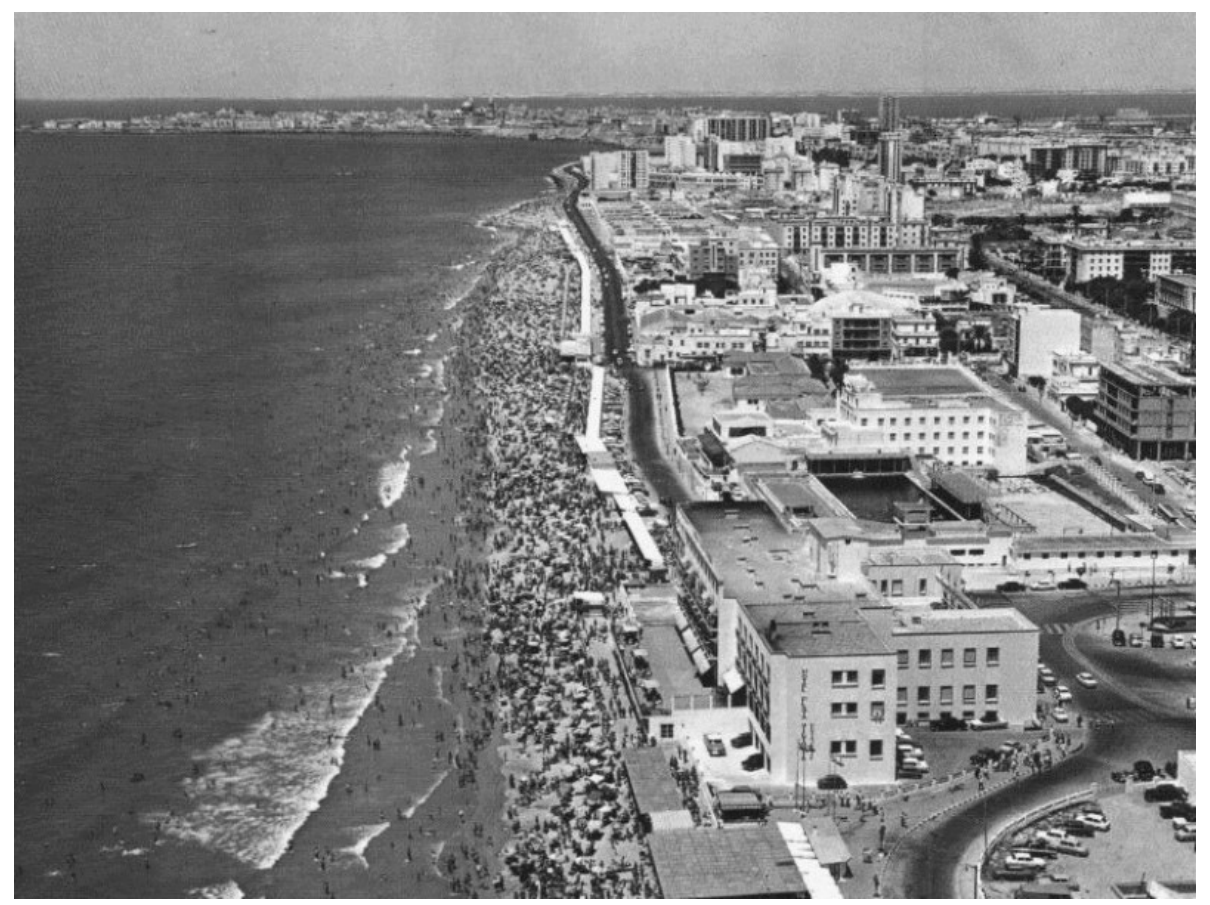

Fig. 3 Littoral coastline at the 80's . No berm or dry beach existed at high tide 
Moreover, the northernmost zone of Victoria beach presents a rocky platform located roughly at the lowest low water level (Bernabeu et al., 2002).

\section{METHODOLOGY}

\section{Field Data}

Within the short term, some sporadic phenomena appear occasionally but which effects may be very important in spite of the little interval of time that they act. So, changes on the profile due to a single storm, not a complete winter season, were also considered. There exist instantaneous damages which are not reversible (v.g.: waves reaching a promenade or building foundation not designed for that chance) and that may remain masked with the observation of averaged longer-term data. That is the reason why to know the order of magnitude of the regression of the coastal line immediately after a storm would be extremely interesting. In addition, it would be noteworthy, as well, to know which is the acretion rate in orther to establish a local defence strategy.

The arrival of the first winter storm in the beginning of November 1995 was known beforehand, thanks to the weather forecast. A daily study of the behavior of the profiles was decided.

Topographic data used in the present work were taken with a distance meter placed on each profile head, using the low tide hours during 21 consecutive days.

The reflector prism was taken by a worker, with a neoprene diving suit, far beyond the -1.00 depth which coincides with the reef flat level. So, the whole profile was surveyed with a $1 \mathrm{~cm}$ reliability. The first field day was $8^{\text {th }}$ November, the storm was on the $11^{\text {th }}$ and the monitoring finished on the $28^{\text {th }}$ of the same month.

\section{Empirical Orthogonal Functions}

Empirical Orthogonal Function (EOF) method has been widely used in coastal geomorphology since Winant et al. (1975) and Aubrey (1978) defined changes in the beach profiles. Among others, Dick and Dalrymple (1984) have applied this technique to the study of the beach profiles and their variation. Losada et al.(1991) applied it to the study of the longitudinal variation of determined contour lines, and Medina et al. $(1991,1994)$ to the sand transport on transversal direction and to the distribution of the sediment grain size along the transversal profile. In addition, Larson et al. (1999) investigated some responses of three beach nourishments at different time and spacial scales. Pruszak (1993) analyzed beach profile changes using Dean's and EOF methods. Furthermore, Muñoz-Perez et al. $(2000,2001)$ studied respectively the behavior of the profile changes due to a fortnightly tidal cycle and the evolution of longshore beach contour lines.

EOF is a statistical method, also known as Principal Component Analysis (PCA), which provides a technique to separate the spatial from the temporal variability of 
beach profile data. A detailed description of the method can be found in statistics text books (e.g. Daultrey, 1976 ; Jackson, 1991). In brief (see fig. 4), if a function $\mathrm{h}=(\mathrm{x}, \mathrm{t})$ represents the profile elevation at a particular position and time, such function may then be defined as a linear combination of scarce spatiality, $\mathrm{h}_{\mathrm{n}}(\mathrm{x})$, and temporal, $\mathrm{e}_{\mathrm{n}}(\mathrm{t})$, eigenfunctions by:

$$
h\left(x_{i}, t_{j}\right)=\Sigma h_{n}\left(x_{i}\right) e_{n}\left(t_{j}\right)\left(\lambda_{n} n_{x} n_{t}\right)^{1 / 2}
$$

where $\mathrm{x}=$ offshore direction; $\mathrm{n}_{\mathrm{x}}=$ number of points in the cross-shore direction; $\mathrm{n}_{\mathrm{t}}=$ number of campaigns carried out to measure the profile elevations and $\lambda_{\mathrm{n}}=$ eigenvalue associated with the $\mathrm{n}^{\text {th }}$ eigenfunction.

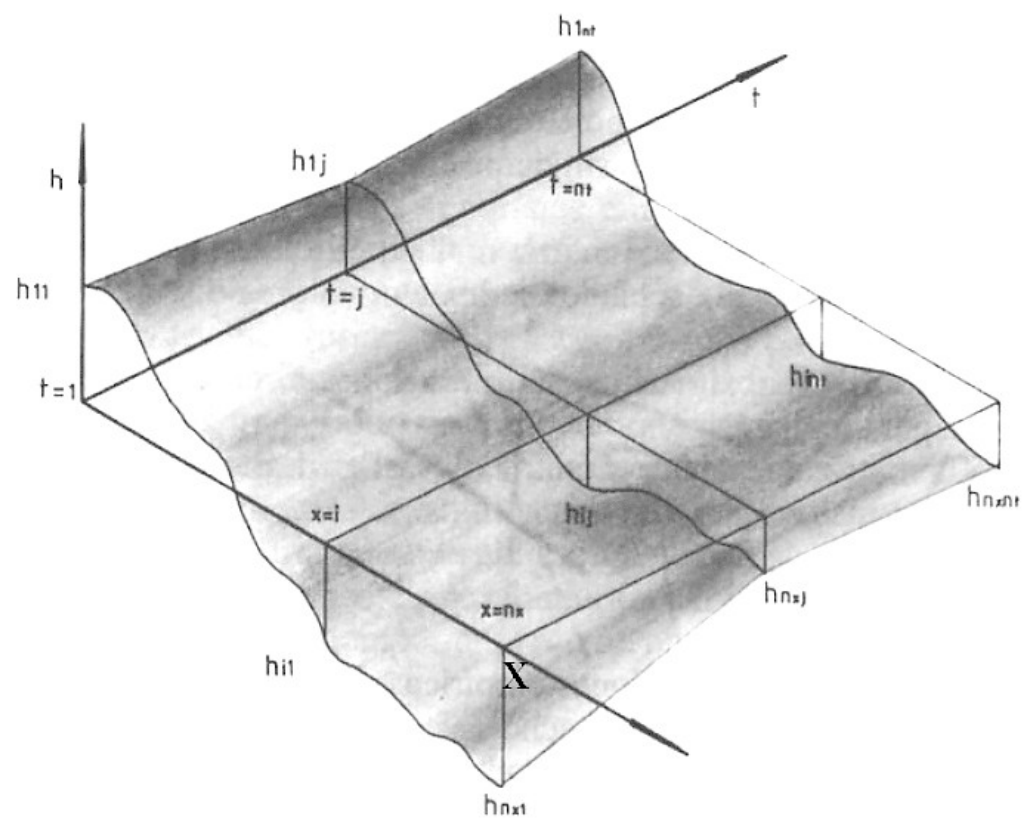

Fig. 4 Sketch of the $n_{t}$ temporal series of $n_{x}$ data each, to be analyzed by means of the EOF; $h_{i j}$ represents the depth of the point $x_{i}$ in the bathymetry $t_{j}$

The eigenfunctions are ranked according to the percentage of the variability which they explain, defined as the Mean Squared Value of the data (MSV). Sometimes (Winant et al, 1975), the mean value is of such importance, when explaining the variability, that it must be removed from the original data in order to allow for better and clearer identification of other smaller, yet important, changes. Then, the MSV turns into the Variance. The first eigenfunction explains most of the mean square value of the data, the second eigenfunction explains the greater part of the remaining MSV and so on. Furthermore, according to Aubrey (1979), assuming that a physical process 
provides most of the profile variability, the corresponding eigenfunction will be related to that phenomenon.

\section{RESULTS}

A graph is shown on Figure 5 where the data set is represented without a previous statistical treatment, and not too many changes can be identified.

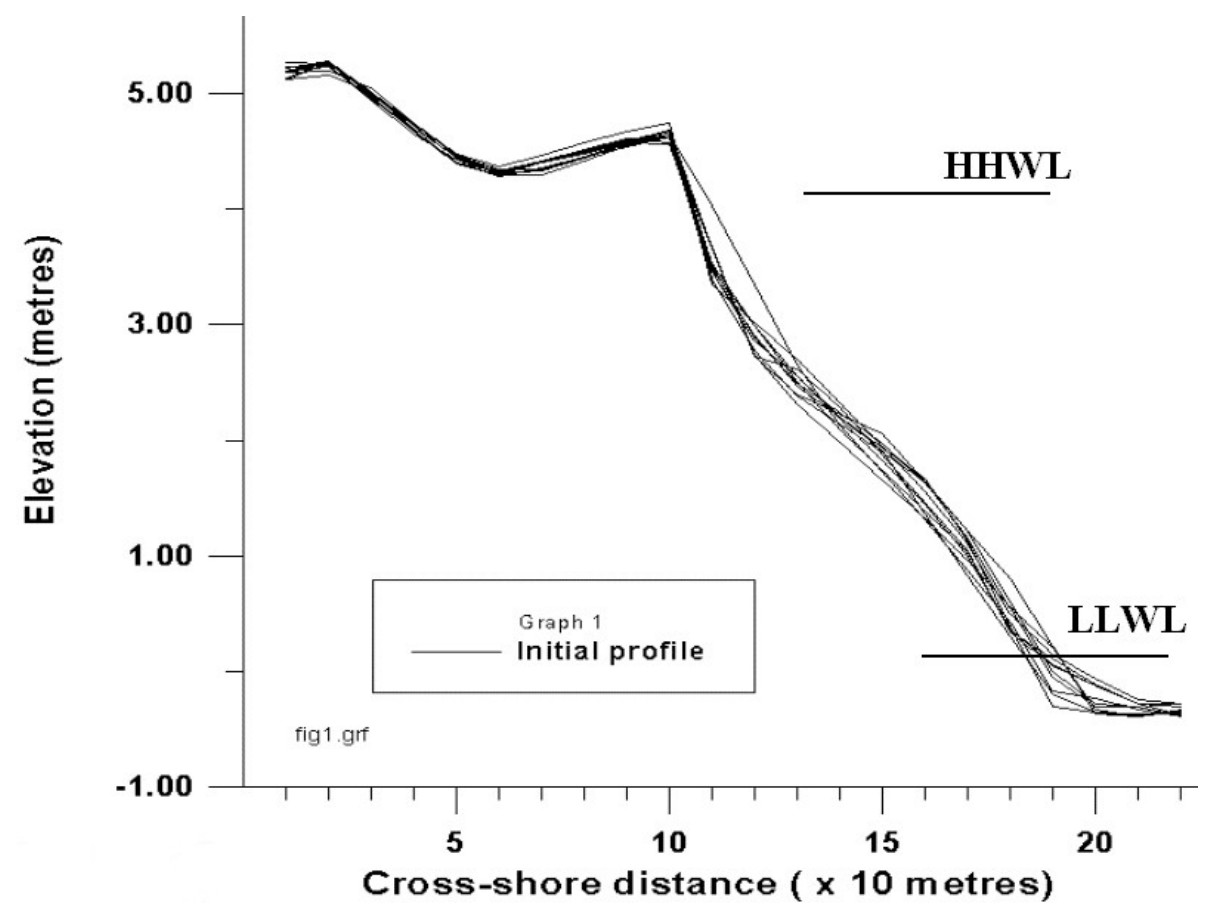

Fig. 5 Data set of profiles taken at the reef flat part of Victoria beach before, during and after a single day storm (without statistical treatment). Highest High Water Level (HHWL) and Lowest Low Water Level (LLWL) are also represented

EOF method was applied to obtain a more clear and complete interpretation of the data variability.

In order to highlight the changes produced by the storm, the original profile has been subtracted from the data prior to the EOF analysis. Figure 6 shows the transversal and temporal EOF components obtained. In order to better identify the relationship between the components and the associated phenomena, the average profile and the tidal range have been included. 

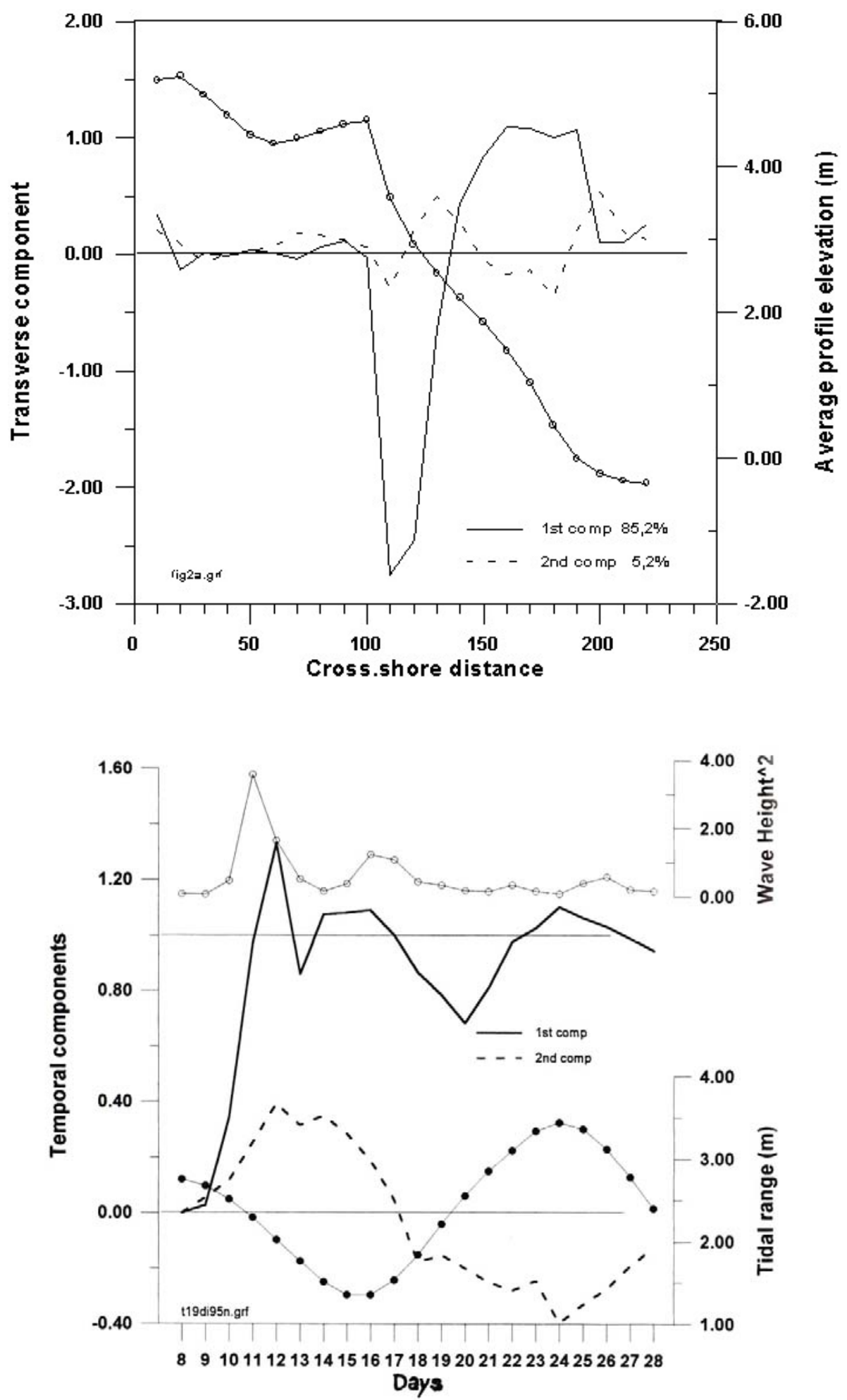

Fig. 6 Cross-shore and temporal components of the levelings taken during the short term monitoring, after the original profile had been subtracted from the data. Average profile, wave energy and tidal range have been plotted too.

The daily average values of the wave climate on those days are shown on fig. 7. 
Together with the significant and average wave height, the square of the average wave height (directly related to the average incident energy) was added. Average period and steepness are also represented. This parameter and the beach slope, according to the Iribarren's number (1951), indicate the type of the foreseen wave breaking. The values oscillate between 0.007 and 0.03 after the storm, what for slopes of $5 \%$ means that the Iribarren's number fluctuates between 0.30 and 0.60 . That is to say, the waves go alternatively from spilling to plunging breaking and thus successively.

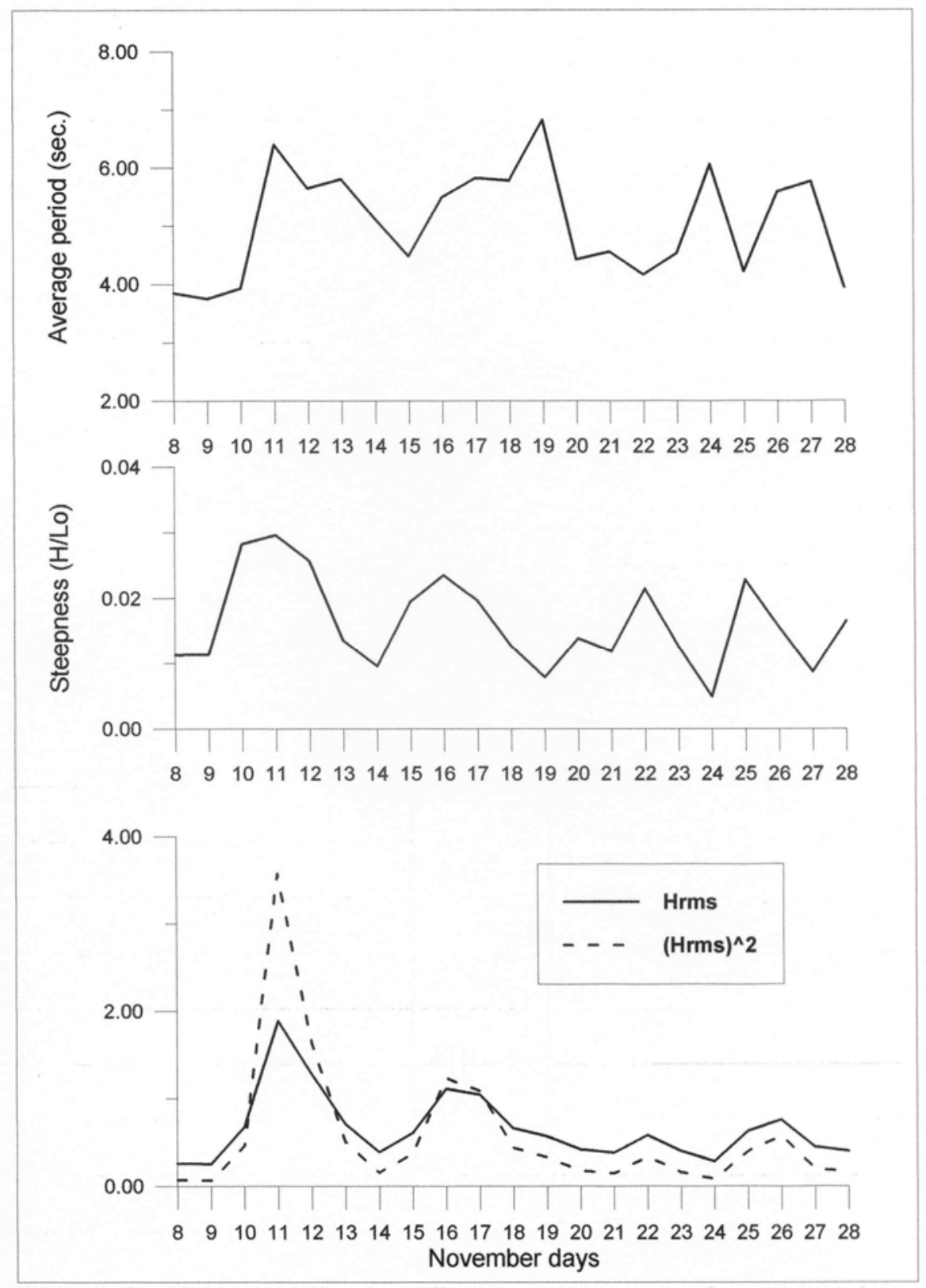

Fig. 7 Daily average value of different wave parameters: period, steepness and DISCUSSION wave height. 
After these results, it was deduced that:

An oscillation of the profile, around the middle of the intertidal zone, can be observed.

The erosion is produced in the higher part of the intertidal zone (see the $1^{\text {st }}$ transversal component, Figure 6) between the +2.50 and +4.50 levels, being more significant between +3.00 and +4.00 . Part of this material is spread in a wider zone immediately lower, between the marks +2.50 and -1.00 . The temporal component associated is always positive; it experiments a strong leap during the storm and it fluctuates around the unit value afterwards. Id est, the slope became milder and the undergone change was not reversible along the monitoring.

In a similar way to Muñoz-Perez et al. (2000), the $2^{\text {nd }}$ component seems to be related to the tidal cycle as it has a sinusoidal shape with a maximum on day 13 and a minimum on day 24 which coincide relatively with the spring and neap tides respectively.

\section{CONCLUSIONS}

The undergone variations of the beach profiles occur at very different scales of time depending on the physical phenomenon that generates them. Within a very short term, the changes provoked by a single day storm have been investigated in this paper.

The EOF (Empirical Orthogonal Functions) allow us to differentiate and distinguish among the different physic phenomena which induce the beach profile changes.

The northernmost zone of Victoria beach, located in the SW coast of Spain, has a reef flat at the lowest low water level. This has allowed monitoring the behaviour of a reefprotected profile by daily topographic levelling during low tide.

Among the conclusions extracted from the research of a reef protected profile facing a single day storm, it should be highlighted that:

- The swing or oscillation point of the reef flat stone is around the middle of the intertidal zone $(+2.00)$.

- For this particular storm, the subduing period of the post-storm fluctuations has been nearly 20 days. Moreover, the erosion has been irreversible in a short term.

- The $2^{\text {nd }}$ component is linked to small oscillations related to a fortnightly variation of the tidal range.

\section{ACKNOWLEDGMENTS}

This study has been partly funded by the Comision Interministerial de Ciencia y Tecnología under contract CTM 2004-04813 /MAR

\section{REFERENCES}

Aubrey, D.G. (1978). "Statistical and Dynamical Prediction of Changes in Natural Sand Beaches”. Ph.D. thesis, Univ. of Southern California, Los Angeles.

Aubrey, D.G. (1979). "Seasonal patterns of onshore-offshore sediment movement". Journal of Geophysical Research, 84 : 6347-6354. 
Bernabeu, A.M., Muñoz-Pérez, J.J. and Medina, R (2002). "Influence of a rocky platform in the profile morphology: Victoria Beach, Cádiz (Spain)”.Ciencias Marinas (2002), 28(2), 1-12.

Dean, R.G. (1977). "Equilibrium beach profiles: U.S. Atlantic and Gulf coasts”. Department of Civil Engineering, Ocean Engineering Report n. 12, University of Delaware, Newark, Delaware.

Daultrey, S. (1976). Principal component analysis. Inst. Br. Geogr. London

Dick, J.E. and Dalrymple, R.A. (1984). "Short and long term beach changes at Bethany Beach, Delaware”. Proc. $19^{\text {th }}$ Intern. Conf. On coastal Engineering, ASCE, Houston, 1650-1667.

Gerritsen, F. (1980). "Wave attenuation and wave set-up on a coastal reef”. Proc. 17th Coastal Eng. Conf., Sydney. ASCE, New York, Vol. 1, pp. 444-461.

Gourlay, M.R., (1994). "Wave transformation on a Coral Reef". Coastal Engineering, 23.

Gutierrez-Mas, J.M., Moral, J.P., Sánchez, A., Dominguez, S. and Muñoz-Perez, J.J. (2003). "Multicycle sediments on the continental shelf of Cadiz (SW Spain)”. Estuarine, Coastal and shelf Science, 57, 667-677.

Hardy, T. and Young, I., (1996). "Field study of wave attenuation of an offshore coral reef”. Journal of Geophysical Research, 101, 14311 - 14326.

Horikawa, K. and Kuo, C.T. (1966). “A study on wave transformation inside surf zone”. Proc. 10th Coastal Eng. Conf. Tokyo, pp. 217 - 233.

Karunarathna, H. and Tanimoto, K. (1995). "Numerical experiments on lowfrequency fluctuations on a submerged coast reef”. Coastal Engineering, 26, $271-289$.

Iribarren, R. (1951). Waves and groins. Ed. Dossat, Madrid (in Spanish)

Jackson, J.E. (1991). A user's guide to principal components. John Wiley \& Sons Inc. New York.

Larson, M. and Kraus, N.C. (1994). "Temporal and spatial scales of beach profile change, Duck, North Carolina”. Marine Geology, 75-94.

Larson M., Hanson, H., Kraus, N.C. and Newe, J. (1999). "Short and long term responses of beach fills determined by EOF analysis". Journal of Waterway, Port, Coastal and Ocean Engineering, 125(6), 285-293.

Losada, M.A., Medina, R., Vidal, C. And Roldan, A. (1991). "Historical evolution and morphological análisis of El Puntal spit, Santander (Spain)”, Journal of Coastal Research, n. 7, pp 711-722

Medina, R., Losada, M.A., Dalrymple, R.A. and Roldan, A. (1991). "Cross-shore and sediment transport determined by EOF method”. Proceedings Coastal Sediments'91, 2160-2174 
Medina, R., Losada, M.A., Losada, I.J. and Vidal, C. (1994). “Temporal and spatial relationship between sediment grain size and beach profile”. Marine Geology, 118, 195-206

Muñoz Pérez, J.J., Tejedor, L. and Medina, R. (1999). "Equilibrium beach profile model for reef protected beaches”. Journal of Coastal Research, 15( 4), 950957.

Muñoz Pérez, J.J., and Medina, R. (2000). "Profile changes due to a fortnightly tidal cycle”. Int. Conf. on Coastal Engineering (ASCE), Sidney, 3063-3075.

Muñoz Pérez, J.J., Medina, R. and Tejedor, B. (2001). "Determination of longshore variations by EOF method in Victoria Beach (SW Spain)”. Scientia Marina, 65(4), 393-402.

Nakaza, E. and Hino, M. (1990). "Reef-zone disaster caused by bore-like surf beat". Flows and waves, Tokyo. Inst. Technology Report n. 5, pp. 85-97.

Nelson, R.C. (1994). ”Depth limited design wave heights in very flat regions”. Coastal Engineering, 23, 43-59.

Pilkey, O., Young, R., Riggs, S.R., Sam Smith, A.W., Wu, H. and Pilkey, W.D. (1993). "The concept of shoreface profile of equilibrium. A critical review”. Journal of Coastal Research n. 9(1), pp 255-278

Pruszak, Z. (1993). “The analysis of beach profile changes using Dean's method and Emprirical Orthogonal Functions”. Coastal Engineering, 19, pp 245-261

Roberts, M.H. (1980). "Physical processes and sediment flux through reef-lagoon systems”. Proc. 17 th Int. Conf. Coastal. Eng., ASCE, 946-962.

Seelig, W.N. (1983). “Laboratory study of reef-lagoon system hydraulics”. Journal of Waterway, Port, Coastal \& Ocean Eng., 109, 380-391.

Symonds, G., Black, K.P. and Young, I.R. (1995). "Wave-driven flow over shallow reefs”. Journal of Geophysical Research, 100, 2639 - 2648.

Winant,C.D., Inman, D.L. and Nordstron, C.E. (1975). "Description of Seasonal Beach Changes using Empirical Eigenfunctions”. Journal of Geophysical Research, 80, 1979-1986.

Yu, X., Isobe, M. and Watanabe, A.(1995). "Wave breaking over submerged horizontal plate”. Journal of Waterway, Port, Coastal and Ocean Eng., 121. 